\title{
The Vioxx ${ }^{\circledR}$ legacy: Enduring lessons from the not so distant past
}

\author{
William F. McIntyre ${ }^{1,2}$, Gerald Evans ${ }^{2}$ \\ ${ }^{1}$ Section of Cardiology, Department of Internal Medicine, \\ University of Manitoba, Winnipeg, Manitoba, Canada \\ ${ }^{2}$ Department of Medicine, Queen's University, Kingston, Ontario, Canada
}

\section{Introduction}

Despite having been voluntarily withdrawn from the market almost 10 years ago, the non-steroidal anti-inflammatory drug (NSAID) rofecoxib $\left(\right.$ Vioxx $^{\circledast}$, Merck \& Co.) remains an infamous and controversial drug in the minds of the public and physicians alike. While it is no longer making its way into prescription bottles, its legacy lives on, in its enduring influences, on drug safety monitoring in the conduct of randomized controlled trials (RCTs) and on modern practices in drug marketing and development.

\section{The Vioxx ${ }^{\circledR}$ story}

Rofecoxib was developed by Merck \& Co. as a cyclooxygenase-2 (COX-2) selective NSAID. The premise behind its pharmacology was simple: it would selectively block the inducible COX-2 iso-enzyme that was important in pain and inflammation without affecting the constitutive COX-1 iso-enzyme that maintains gastrointestinal (GI) mucosa integrity and mediates platelet function. This selectivity would make it the preferred choice over non-selective NSAIDs such as naproxen and ibuprofen, offering pain control with a reduced risk of adverse effects on GI and platelet function.

The United States Federal Food and Drug Administration (FDA) approved rofecoxib for the treatment of osteoarthritis in early 1999. The approval was based on its efficacy and safety in phase II and III RCTs. Thereafter, Merck \& Co. began an ambitious marketing campaign for the drug, including various mass media advertisements aimed at active middle-aged patients. The advertisement efforts included soliciting the endorsement of celebrities such as Olympic gold medal-winning figure skater Dorothy Hamill to promote the product. The campaign was a great success; over 100 million rofecoxib prescriptions were written in the United States in its first 12 months on the market.

Just as rofecoxib was escalating in popularity as a prescription NSAID, the clinical trial that would result in its ultimate demise was coming to a conclusion. Published in 2000, The VIGOR trial compared GI side effects in rheumatoid arthritis patients taking rofecoxib vs. naproxen [1]. The 8,076 patient, multi-center, randomized, double blind study found a statistically significant relative risk reduction of $50 \%$ for GI events in the patients on rofecoxib; it was a success for Merck \& Co. and their marketing efforts for the drug. Unfortunately, the study also revealed an unexpected increase in the risk of cardiovascular (CV) events. In an interim analysis of the data, it was apparent that patients randomized to rofecoxib had more $\mathrm{CV}$ events. The authors postulated that this difference was due to an "acetylsalicylic acid (ASA)-like anti-platelet effect" of naproxen. In the published version of the trial, $0.4 \%(\mathrm{n}=17)$ of the patients on rofecoxib were reported as having suffered myocardial infarctions (MI's) compared to only $0.1 \%(\mathrm{n}=4)$ of those on naproxen. Ultimately, the authors attributed this difference to the fact that a small group of study subjects who met criteria for ASA for secondary CV prophylaxis but were not receiving ASA (4\%) accounted for a disproportionate percentage (38\%) of the MI's. It would, however, later come to light that Merck \& Co. knew about, but did not report, all of the MI's that occurred among the rofecoxib patients. The

Address for correspondence: William F. McIntyre, BSc, MD, Adult Cardiology Fellow, Cardiac Sciences Program, University of Manitoba, e-mail: wfmcintyre@gmail.com 
study had a GI event reporting cutoff date of March 2000 , however CV events were only reported up to February 2000. An additional three MI's occurred in the final month of the study and were known to the steering committee at the time of final submission, but were not reported in the published manuscript [2]. This apparent concealment of adverse events would become more widely known a few years later after the results of the APPROVe trial became known. This placebo-controlled trial evaluated secondary chemoprevention of colorectal cancer with rofecoxib and included pre-specified $\mathrm{CV}$ secondary endpoints, finding a relative risk of 1.92 (95\% CI 1.19-3.11, $\mathrm{p}=0.008$ ) for CV events in patients taking rofecoxib compared to placebo [3]. After learning these data, Merck \& Co. voluntarily withdrew Vioxx ${ }^{\circledR}$ from the market, citing it was the most reasonable course of action [4]. However, lawsuits and subsequent investigations uncovered the knowledge of the three "hidden MI's" and further drove speculation and proceedings around this drug both in the academic and public fora.

\section{Aftermath}

Numerous opinions and analyses were published following the withdrawal of rofecoxib. A 2005 editorial re-analyzed the VIGOR CV safety outcomes with omission and inclusion of the "three hidden MIs" - finding an increase in the relative risk of having an MI on rofecoxib to 5.0 (95\% CI 1.68-20.13) [2]. With respect to the authors' initial speculation that naproxen may have had an ASA-like antiplatelet effect in the VIGOR trial, serious doubt is cast on this hypothesis when the relative risk of the thrombotic events among patients on naproxen in the VIGOR trial (RR 0.42, 95\% CI 0.25-0.072) is compared against the antiplatelet benefit from the antithrombotic trialist's collaboration (RR 0.78, 95\% CI 0.74-0.82). Even controlling for differences in study procedures and patient populations, it was hard to defend a nearly 2 -fold difference in the relative risk [5].

Running in parallel with the academic analyses were mass media and legal campaigns - images of which still endure in the public's consciousness. Viox $\mathrm{x}^{\circledast}$ was the subject of billboards, television, internet and magazine advertisements and talk shows. It is estimated that up to 88,000 patients in the United States alone had an MI while taking Vioxx ${ }^{\circledast}$. There were some 13,000 lawsuits by 47,000 plaintiffs and Merck \& Co. established a US $\$ 4.85$ billion fund to settle the lawsuits [6]. In 2011, Merck \& Co. would be levied a $\$$ US
950 million penalty for illegal marketing [7]. The investor lawsuits remain unsettled to date.

The influence of the Vioxx ${ }^{\circledR}$ legacy is enduring today and encompasses 3 principal themes: changes in the field of pharmacovigilance, a better understanding of COX biology and its role in inflammation and, finally, drug development, reporting and marketing in the determination of drug safety.

In the aftermath of the Vioxx ${ }^{\circledR}$ story and that of other contemporary and controversial drugs such as prucalopride (Resolor ${ }^{\circledR}$, Johnson \& Johnson), there were wide-sweeping changes in the practice of pharmacovigilance [8]. Pharmacovigilance is defined as a set of practices aimed at the detection, understanding and assessment of risks related to the use of drugs in a population and the prevention of consequential adverse effects [9]. Regulating bodies such as the United States FDA now impose tighter regulations on how safety data is to be collected and reported. Whereas a large part of drug development was often focused on efficacy, these changes now give the reporting of safety a more important role both in the pre- and post-marketing phases of drug development.

Based on the Vioxx ${ }^{\circledast}$ case, we have a better understanding of COX biology and inflammation. The premise behind the pharmacology of selective COX-2 inhibition was that if it could selectively block the inducible iso-enzyme that stimulated pain and inflammation, it would allow the constitutive COX-1 iso-enzyme to maintain GI mucosal integrity and mediate platelet function. Unfortunately, the result was an increase in thrombotic risk. We now know that selective COX-2 inhibition decreases vascular prostacyclin and may affect the balance between prothrombotic and antithrombotic eicosanoids. Unlike the platelet inhibition afforded by COX-1 inhibitors, COX-2 inhibitors do not share this antithrombotic property. In contrast, by decreasing vasodilatory and antiaggregatory prostaglandin production, COX-2 antagonists appear to tip the balance in favor of the prothrombotic molecules that may lead to increased CV thrombotic events $[5,10]$.

The third theme within the Vioxx ${ }^{\circledR}$ legacy is still evolving. The research and development of rofecoxib, like many prescription drugs on the market today, was funded in large part by the investment of private capital. The financial fallout of Vioxx ${ }^{\circledR}$ and its subsequent scandal are not yet completely settled. As a result of the Vioxx ${ }^{\circledR}$ legacy, companies and investors alike will, without any doubt, take lessons from the final legal and financial consequences in designing future investment strategies. 


\section{Conclusions}

While the developers of rofecoxib hoped it would be a "magic bullet" for pain relief, ultimately it had an unexpected adverse effect and brought harm to many. Despite its adverse effects, Vioxx ${ }^{\circledR}$ did give symptomatic relief to millions of patients. Some still swear to this day that they would trade the improved quality of life afforded to them by rofecoxib for even a doubling in their own risk of a heart attack. While the numbers of people who had events were large, they are small as a proportion of those who actually took the drug. One can only speculate, if Viox ${ }^{\circledast}$ had only been studied more carefully and marketed less ambitiously, might it have been possible to identify patients that would have benefited from the drug while preventing its use in those most at risk for a CV event? We will never know the answer to this question but the legacy of Vioxx ${ }^{\circledast}$ lives on and continues to affect us today. One can only hope that drug manufacturers, regulators, clinicians and the public are able to take lessons from Vioxx ${ }^{\circledR}$ to more responsibly bring products to market in an ethical and transparent way.

Conflict of interest: none declared

\section{References}

1. Bombardier C, Laine L, Reicin A et al. Comparison of upper gastrointestinal toxicity of rofecoxib and naproxen in patients with rheumatoid arthritis. N Engl J Med, 2000; 343: 1520-1528.

2. Curfman GD, Morrissev S, Drazem JM. Expression of concern: Bombardier et al. "Comparison of upper gastrointestinal toxicity of rofecoxib and naproxen in patients with rheumatoid arthritis". N Engl J Med, 2000; 343: 1520-1528. N Engl J Med, 2005; 353: 2813-2814.

3. Bresalier RS, Sandler RS, Quan H et al. CV events associated with rofecoxib in a Colorectal Adenoma Chemoprevention Trial. N Engl J Med, 2005; 352: 1092-1102.

4. Merck, "News Release: Merck Announces Voluntary Withdrawal of Vioxx ${ }^{\circledR}$ ", September 30, 2004, http://www.merck.com/newsroom/vioxx/pdf/vioxx press release final.pdf.

5. Wright JM. The double-edged sword of COX-2 selective NSAIDs. CMAJ, 2002; 167: 1131-1137.

6. Prakash S, Valentine V. Timeline: The Rise and Fall of Vioxx. November 10, 2007, http://www.npr.org/templates/story/story. php? storyId $=5470430$.

7. Wilson D. Merck to Pay $\$ 950$ Million Over Vioxx. New York Times. November 22, 2011, http://www.nytimes.com/2011/11/23/ business/merck-agrees-to-pay-950-million-in-vioxx-case.html.

8. Zwillich T. How Vioxx is changing US drug regulation. Lancet, 2005; 366: 1763-1764.

9. Langlitz N. Pharmacovigilance and post-black market surveillance. Soc Stud Sci, 2009; 39: 395-420.

10. Armstrong PW. Balancing the cyclooxygenase portfolio. CMAJ, 2006; 174: 1581-1582. 